\title{
Computer systems and CAD/CAE in teaching engineering
}

\begin{abstract}
The paper presents the integration of computer systems and CAD/CAE herramintas in neseñanza of engineering through scientific groups-Student. By employing the fundamentals of Analysis and Synthesis engineering through scientific groups-Student. By employing the fundamentals of Analysis and Synthesis Systems Engineering you can come to understand the functional and structural principles of machines and equipment, describe them mathematically; make your CAD design and simulation; and even optimizing their performance. It has developed the WISDOM systemic of students apply the skills and knowledge acquired in basic training. This paper presents the results achieved by students who design spiral pump, compressed air engine a stander, a dummy for sports training, a pickup truck solid waste are exposed; and modeling the angle of the rotor blades of the wind farm Gibara II and maintenance management, among others.
\end{abstract}

Keywords: learning, mechanical engineering, design, CAD/CAE, FRE
Volume 5 Issue I - 2019

\author{
Javier Vargas, Carlos Alberto Varela Trinchet, \\ Roberto Pérez Rodríguez \\ Director of the Center for CAD/CAM Studies, Colombia
}

Correspondence: Javier Vargas, Department of Holguin, Cuba, Director of the Center for CAD/CAM Studies, Colombia, Email javier.vargas@campusucc.edu.co

Received: February II, 2019 | Published: February 18, 2019

\section{Introduction}

The origins of the art dating back to the emergence of the wheel in $3500 \mathrm{aC}$ Mesopotamia, ${ }^{1}$ a current assessment of the event allows us to appreciate that only it was possible to explain in detail associated with two important discoveries: the shape of the planet earth and the mathematical calculation of the area. This shows us how imagination, knowledge and creativity are essential prerequisites for the emergence of equipment and mechanical appliances that appear to be simple. Understand how they are constructed and operate, it is a complex task; replicate or even achieve improved designs requires a set of qualities and unusual skills. In this research a pedagogical proposal that articulates coherently the undergraduate program of the School of Mechanical Engineering manner, the fundamentals of design and aided engineering computer (CAD/CAE) and the Analysis and Synthesis Systems Engineering is performed (ASSI). It shows how students 4 to and 5 to year can independently come to understand the functional and structural principles of ecological machinery and equipment and even to design and optimize them. It is hoped that dominate some of the essential methods of attaining knowledge during the investigation, ways to assume" who does not know that it can take as many forms as arising from the reality under study and creative potential of researcher. $^{2}$

\section{Development}

The complexity of the process in Mechanical Engineering is to work with principles, fundamentals and intangible, difficult to observe variables; as mechanical stresses; and electrical (that interact with mechanical devices) heat fluxes, liquid, energy transformations. All with a chance to be quantified and modeled. They are also considered qualitative variables associated with the performance of man's interaction with the environment as well as aesthetics, beauty products, constructive ways and presentation; the Researchers assume that this requires their overall systemic assessment; beyond one or another research paradigm. ${ }^{3,4}$ To overcome this difficulty have created models, procedures and systems, practical and verifiable manner, diagnose the equipment involved (restore or maintain) and check the technical condition. This elementary but very complex to implement, logic is able to ensure high reliability and comfort in all such means we use daily, this factual thinking is also used in medicine, agriculture and other sciences. ${ }^{5}$ It is known to have broad application to the CAD/ $\mathrm{CAM} / \mathrm{CAE},{ }^{6}$ used in the practice of engineering at various stages of the life cycle of products, including drawing, design, simulation, analysis and manufacturing. You cannot say the same of ASSI, which is a philosophy of work to optimize, widely used in technical sciences, but given its complexity is not taught in undergraduate and even graduate in a few versions in Cuba. The authors assume that given the knowledge and mastery of ICT that have the current generation of undergraduates; they are "native" of that technology; and of course the influence of the work that the CE CAD/CAM, there are conditions optionally, provide learning Essential basics Systems Engineering.

\section{Characterization analysis and synthesis systems engineering}

What levels of knowledge requires the ASSI? Why use necessary? Where and how you can use different models and methods? Systems Engineering, ${ }^{7,8}$ is a way of interdisciplinary approach that allows studying and understanding the reality, in order to implement or optimize complex systems. You can see how the technological application of systems theory, mathematical modeling and simulation; integrates (engineering) disciplines and specialties with the use of the natural sciences (mathematics, physics, chemistry) to model systems that allow rational use of material resources and human capital, in the interests of increasing the efficiency of processes technology. Sometimes systems engineering computer engineering or computer science is confused, which involved substantially, but part of the multidisciplinary approach. Systems Engineering for use as mathematical assurance can be classified into optimal design of systems, processes, equipment, parts, tools, tasks generation technologies and optimal production management. ${ }^{9}$ considers this as an engineering vision that incorporates no longer mainly differential and integral calculus, but not only qualitative mathematics and mathematics related to rigid, stable and mechanical systems. In short, it is open to other sciences and engineering disciplines and not just applied mathematics and engineering that explore solutions. 


\section{How to teach students these basics so that they are affordable and pique your interest}

On these assumptions, the possibility of using this factual engineering student thinking is appreciated, so focused to a specific mechanical equipment; You can answer the essential questions: what is it?, what is it?, what, how construction works, I can improve it. This overcomes the limitations of verbal information received in a class and turn it into a research task which assumes budgets, inquire, sort and process information; observe, analyze and compare, to finally make an informed position to the existing knowledge. It is intended that the student relates the object of research with learning and what will know. This type of education there are different methods and used in European schools widely pedagogical approaches, casebased reasoning, project-based learning, among others, certain applications in our country for technical education. ${ }^{10-12}$ In the case of, ${ }^{13,14}$ are developing methods investigative independence, the skills to seek knowledge and process assuming positions substantiated. To develop the students "they need to use higher-order intellectual skills and also learn to work together. They must listen to others and also be able to clearly express his ideas. Be able (sic) to read different types of materials and express themselves in different formats. These are called key capabilities for the XXI Century". ${ }^{15}$ The authors consider among its limitations sometimes does not reveal other variations, trends and especially pay attention to avoid falling into simplistic, reductionist or positivistic positions. To get the student by itself solve these tasks requires a systematic and coherent preparation should be supplemented during the development of their skills and abilities, from the third year of the race; and with the vision of a team or selected by the machine; which is the concrete output all evaluations, practical work and projects, culminating with his thesis.

\section{Procedure for procedure}

It is based on established concepts of analysis and synthesis processes. Aware that almost none of the processes, phenomena and even objects are so basic and simple as we imagined and the preceding culture had shown us. The atom is a highly complex system, which occupies countless talents in the world." That has been known since the dawn of 1960 " nothing or almost nothing is linear, additive and weak relations", ${ }^{16}$ so special attention to teaching Systems Analysis is provided. Here a research position that identifies the object of research student (equipment, machine, system) as part of a larger system is adopted, but intended to fulfill a function to other subsystems, in interaction with humans and the environment. Modeling in some of its variants applied as cognitive possibilities of the investigation process and the tools available. There have been theoretical, mathematical and iconic models. Emphasis is placed on learning traffic in that order because in fact the ultimate goal is to achieve the CAD design team. Simulation is one of the basic methods thereby reproduce in static conditions with simple parameters and then, according to the possibilities with multiple parameters and interactions; sometimes to the transient simulation and dynamics. This reproduction process conditions improved optimization or sometimes object. Common in mechanics, engineering necessary to understand the operation of equipment phenomena are: the behavior of fluids such as air, water, temperature, kinetic energy; the ability of a compartment, the stresses in a structure (which must be resisted, but not be oversized), to that other indicators of efficiency and power, endurance, productivity, pressure, economy, etc. bind. These phenomena have been reproduced partially (being subjective models) in the specialized software Flow Simulation or own Solid Work; Python, Excel and Matlab. They can be improved through mathematical and computational simulations. Finally, given the different options suitable design and sometimes optimal; It joins the CAD design complete cycle (not closed, is cyclical and iterative). The improved design of the object carried by the comprehensive knowledge: Here the final product is obtained. Clearly, this procedure requires a comprehensive training of teachers and a multidisciplinary group that can channel and answer all questions arising in the investigation. They should have the ability to troubleshoot problems in the research process on the basis of "methodological flexibility and versatility, knowing the possibilities and limitations of each strategy". ${ }^{2}$ Have been incorporated mathematicians, computer scientists, designers and engineers $\mathrm{CAD}$ companies pursuing masters and doctorate, with concerns and common tasks. This is not to teach the constructive and functional elements, or deliver detailed and copious information with all possible variants. It is intended that starting from the suitable employment foundations methods such as analysis, synthesis, modeling, simulation and optimization, students select and apply the information they need. With these methods students analyzed phenomena to achieve the maximum power of an air motor and a spiral pump to determine the optimum angle of the blades of a wind turbine, reducing the weight and cost of a standing frame for children with severe physical limitations, bring the size and shape of a mannequin human model under cost constraints and aesthetic. They also catered to design feasibility under a picker truck solid waste; and modeling more complex and systemic processes to determine some of the critical indicators of maintaining the Gibara II wind farm and transport fleet in Transcupet. The main results obtained are shown highlighting the theoretical and practical impact.

\section{Conclusions}

I. By employing fundamentals Analysis and Synthesis Systems Engineering with $\mathrm{CAD} / \mathrm{CAM}$ tools, you can come to understand the functional and structural principles of machines and equipment, describe mathematically; make your CAD design and simulation; and even optimizing their performance.

II. Managed to develop systems thinking of students apply the skills and knowledge acquired in basic training.

III. Emphasis is placed on the procedural part of the investigation. Students are able to apply concepts and methods of advanced scientific research.

IV. It is vital the comprehensive training of teachers and character multidisciplinary faculty group.

\section{Acknowledgments}

None.

\section{Conflicts of interest}

The author declares there is no conflict of interest.

\section{References}

1. Bernal JD, Havana, Arzola J. Proposal Selection, Ed Scientific Technical, Engineering Systems. (Foreword and introduction). Science in history. Technical scientist. 2007

2. Ruiz Iglesias, Magalys. The Competition Investigator. Entrevista on tutoring to Educational Research (digital). 2009.

3. Reichardt ChS, Cook TD. Towards overcoming the confrontation between qualitative and quantitative methods. Qualitative and quantitative methods in evaluation research, Madrid, Morata, 1986. 
4. Cruz M, Campano AE. Processing information in educational research. Havana: Cuban Education. Hurtado Ortega, J. multiobjective optimization of the parameters involved in bending processes cylindrical metal tubes by the entrainment method. 2008 .

5. Sanetti Vilá, Oscar. The research in military medicine. Editora Green Olivo, Havana. 1985.

6. Ahmed W. Virtual Manufacturing. London, England. 2011.

7. Arzola J. Proposal Selection, Ed Scientific Technical Engineering Systems, Ed Felix Varela, Havana. 1989.

8. Hurtado Thesis option presented in the scientific degree of Doctor of Technical Sciences, Havana. 2012.

9. Maldonado E. Engineering of complex systems, panorama and opportunities. Argentina. 2014.

10. Cobo Ortega A. Mathematical models and tools for decision making. Conferences University of Holguin, (digital). Chagoyen Mendez, Caesar Case-Based Reasoning: A path for design gear. 2007.
11. Minujin A. The creativity is learned. Magazine Volume XIX Educational, Havana. 1989.

12. Swartz Robert J. Thinking Based Learning. Promoting Quality Student Achievement in the 21st Century. Columbia University, New York USA. Uroski, Vladimír. 2008.

13. Chibás Ortis, Felipe. Creativity and group dynamics. Editorial Pueblo and Education, Havana. 1992.

14. Martinez Sanchez, Natalia, Maria Matilde, et al. Model for designing teaching-learning systems using intelligent case-based reasoning.

15. Larmer, John, John R. Mergendoller of Buck. The Main Course, Dessert not.

16. Von Bertalanffy, Ludwig. Methodology of scientific knowledge. General System Theory, Foundations, Development, Applications. Mir Publishers, Moscow. 1968. 